\title{
Ambulance use affects timely emergency treatment of acute ischaemic stroke
}

\author{
KK Lau *, Ellen LM Yu, MF Lee, SH Ho, PM Ng, CS Leung
}

\section{A B S T R A C T}

Introduction: For acute ischaemic stroke patients, treatment with intravenous tissue plasminogen activator within a 4.5-hour therapeutic window is essential. We aimed to assess the time delays experienced by stroke patients arriving at the emergency department and to compare ambulance users and non-ambulance users.

Methods: We performed a prospective cohort study in a tertiary hospital in Hong Kong. All acute stroke patients attending the emergency department from January to June 2017 were recruited. Patients who were in hospital at the time of stroke onset and those who transferred from other hospitals were excluded. Three phases were compared between ambulance users and non-ambulance users: phase I, between stroke onset and calling for help; phase II, between calling for help and arriving at the emergency department; and phase III, between arriving and receiving medical assessment.

Results: Of 102 consecutive patients recruited, 48 (47\%) patients arrived at the emergency department by ambulance. The percentage of stroke patients attending emergency department within the ambulance users than for non-ambulance users (64.6\% vs $29.6 \%$; $\mathrm{P}<0.001)$. For phases I, II and III, the median times were significantly shorter for ambulance users (77.5, 32 and $8 \mathrm{~min}$, respectively) than for non-ambulance users (720, 44.5 and $15 \mathrm{~min}$, respectively; all $\mathrm{P}<0.001$ ).

Conclusion: Transport of patients to the emergency department by ambulance is important for timely and effective stroke treatment.

\section{Hong Kong Med J 2018;24:335-9}

\section{DOI: $10.12809 / \mathrm{hkmj} 177025$}

${ }^{1}$ KK Lau *, FRACP, FHKAM (Medicine)

${ }^{2}$ ELM Yu, BSc (Stat \& Fin), MSc (Epi \& Biostat)

${ }^{1}$ MF Lee, BS (Nursing), MSc

${ }^{1}$ SH Ho, BS (Nursing)

${ }^{1}$ PM Ng, BS (Nursing), MSc

${ }^{3}$ CS Leung, FHKCEM, FHKAM (Emergency Medicine)

${ }^{1}$ Department of Medicine and Geriatrics

2 Clinical Research Centre

${ }^{3}$ Accident and Emergency Department

Princess Margaret Hospital, Laichikok, Hong Kong therapeutic window was significantly higher for * Corresponding author: laukk2@ha.org.hk

New knowledge added by this study

- Significantly more ambulance users received medical consultation at the emergency department within the therapeutic window than non-ambulance users.

- Time intervals between stroke onset, help seeking, arrival at the emergency department and medical consultation were significantly shorter for ambulance users than for non-ambulance users.

- Non-ambulance users who had visited a general practitioner arrived at the emergency department significantly later than ambulance users after seeking help; those who did not visit a general practitioner were not significantly different from ambulance users.

Implications for clinical practice or policy

- The public should be educated to promptly call the emergency services after stroke onset.

\section{Introduction}

Treatment for acute ischaemic stroke by intravenous tissue plasminogen activator (TPA) was introduced in $1995 .^{1}$ Early attendance is essential, as the effectiveness of TPA has been shown to decrease over time. ${ }^{2,3}$ Stroke patients are recommended to receive TPA within 4.5 hours after stroke onset. ${ }^{1,2}$ In Hong Kong, TPA has been available since early 2010. It typically takes 1 hour to complete the necessary examination, blood tests, brain computed tomographic scan, and preparation of TPA for administration. Therefore, stroke patients should receive a medical consultation at an emergency department (ED) within the therapeutic window of 3.5 hours after onset. In 1999, a study in Hong Kong investigated how patients attended EDs after stroke. ${ }^{4}$ At that time, stroke was classified as category II, and patients were not treated as urgent. Therefore, such stroke patients were often seen several hours after arrival. The study suggested that stroke should be treated as category I, and that immediate treatment should be given. ${ }^{4}$ Public education on recognising the signs and symptoms of stroke was also recommended. ${ }^{4}$ A collective effort at the social 


\section{使用救護車如何影響急性缺血性中風病人能否 接受及時的治療}

劉國光、余洛汶、李明輝、何淑嫻、吳佩雯、梁展新

引言：對急性缺血性中風患者, 能夠在4.5 小時的治療窗口期內使用靜 脈組織纖溶酶原激活劑治療至關重要。本研究旨在比較救護車使用者 和非救護車使用者所經歷的時間, 並分析他們能否在治療窗口期內抵 達急症室的關係。

方法: 我們在香港一所分區醫院進行前瞻性隊列研究, 招募所有於 2017 年1月至6月期間經急症室入院的中風患者。中風時已住院或由 其他醫院轉介的患者則被排除。本研究比較中風後救護車使用者和非 救護車使用者的三個時段：由中風發生到尋求協助所需時間（第一時 段）、由尋求協助至到達急症室所需時間（第二時段）, 以及由到達 急症室到接受醫療評估所需時間（第三時段）。

結論：在連續招募的102名患者中，48名（47\%）患者通過救護車到 達急症室。治療窗口期內到達急症室的中風患者比例明顯高於非救護 車使用者（64.6\%比 $29.6 \% ； \mathrm{P}<0.001 ）$ 。在上述的三個時段, 救護 車使用者的中位時間（分別為77.5、32和 8 分鐘）比非救護車使用者 （分別為720、44.5和 15 分鐘； $\mathrm{P}<0.001$ ) 明顯較短。

結論：通過救護車將患者運送到急症室對於及時有效的中風治療非常 重要。 from patient interviews and electronic admission records. The collected data were cross-checked by relatives or a GP. Three time intervals were studied: phase I was between stroke onset and calling for help (calling the emergency services for ambulance users or other calls for help for non-ambulance users); phase II was between calling for help and arriving at the ED; and phase III was between arriving at the ED and receiving medical consultation. The percentage of stroke patients receiving a medical consultation within the therapeutic window (210 minutes from stroke onset) was compared between ambulance users and non-ambulance users using Pearson's Chi squared test. The time intervals of the three phases were reported as median (interquartile range) and were compared between the two groups using the Mann-Whitney $U$ test.

\section{Results}

A total of 102 patients were eligible and were consecutively recruited. Of these patients, 48 (47.1\%) were brought to the ED by ambulance. Patient demographic data, including age, sex, and co-morbidities are presented and compared between ambulance users and non-ambulance users in Table 1. No statistical difference was found between the two groups except hypertension $(\mathrm{P}=0.016)$.

The proportion of stroke patients arriving within the therapeutic window was significantly higher in ambulance users $(64.6 \% ; 31 / 48)$ than that in non-ambulance users $(29.6 \% ; 16 / 54)[\mathrm{P}<0.001]$. Of the 12 non-ambulance users who visited a GP before going to the ED, only one (8.3\%) arrived within the therapeutic window, compared with 15 out of $42(35.7 \%)$ patients from the non-ambulance user group.

Table 2 shows the comparison of the different time intervals between ambulance users and nonambulance users. There were significant differences between the two groups for all phases $(\mathrm{P}<0.001)$. The median time for phase I for ambulance users was 77.5 minutes, whereas for non-ambulance users it was 720 minutes. The non-ambulance user group, whether the patient visited a GP or not, had a longer phase I interval than the ambulance user group (1470 [720-3165] min; $P=0.001$ for those who visited a GP and 440 [75-3023] $\mathrm{min} ; \mathrm{P}=0.004$ for those who did not visit a GP). For phase II, the median travel time for ambulance users (32 min) was significantly shorter than that for non-ambulance users (44.5 $\min )[\mathrm{P}<0.001]$. Compared with ambulance users, non-ambulance users who had visited a GP had a significantly longer travel time (76 [56.25-123] min; $\mathrm{P}<0.001)$, whereas the travel time for those who did not visit a GP was not significantly different (31.5 [19.5-52.5] min; $P=0.743)$. After arrival at the ED, the time to medical consultation for ambulance users was 8 minutes and that for non-ambulance 
TABLE I. Demographic characteristics of non-ambulance users and ambulance users*

\begin{tabular}{|c|c|c|c|c|c|c|c|}
\hline & \multirow{2}{*}{$\begin{array}{r}\text { Ambulance } \\
\text { users }(n=48)\end{array}$} & \multicolumn{4}{|c|}{ Non-ambulance users $(n=54)$} & \multirow[t]{2}{*}{$P$ valuet } & \multirow[t]{2}{*}{ All $(n=102)$} \\
\hline & & $\begin{array}{c}\text { Visited GP } \\
(n=12)\end{array}$ & $\begin{array}{l}\text { Did not visit } \\
\text { GP ( } n=42)\end{array}$ & $\mathrm{P}$ value & All & & \\
\hline Age (years) & $65.0 \pm 14.9$ & $54.5 \pm 8.6$ & $61.4 \pm 11.9$ & 0.067 & $59.9 \pm 11.5$ & 0.050 & $62.3 \pm 13.4$ \\
\hline Male sex & $30(62.5)$ & $10(83.3)$ & $26(61.9)$ & 0.298 & $36(66.7)$ & 0.660 & $66(64.7)$ \\
\hline Ever smoking & $13(27.1)$ & $7(58.3)$ & $11(26.2)$ & 0.079 & $18(33.3)$ & 0.493 & $31(30.4)$ \\
\hline Hypertension & $31(64.6)$ & $7(58.3)$ & $15(35.7)$ & 0.194 & $22(40.7)$ & 0.016 & $53(52.0)$ \\
\hline Diabetes mellitus & $15(31.3)$ & $3(25.0)$ & $11(26.2)$ & 1.000 & $14(25.9)$ & 0.552 & $29(28.4)$ \\
\hline Hyperlipidaemia & $19(39.6)$ & $2(16.7)$ & $14(33.3)$ & 0.474 & $16(29.6)$ & 0.291 & $35(34.3)$ \\
\hline Atrial fibrillation & $8(16.7)$ & 0 & 5 (11.9) & 0.575 & $5(9.3)$ & 0.263 & $13(12.7)$ \\
\hline History of strokeł & $28(59.6)$ & $8(66.7)$ & $20(50)$ & 0.310 & $28(53.8)$ & 0.566 & $56(56.6)$ \\
\hline
\end{tabular}

Abbreviation: GP = general practitioner

* Data are shown as mean \pm standard deviation or No. (\%), unless otherwise specified

+ Pearson's Chi squared test, independent $t$ test, or Fisher's exact test

‡ Due to missing information, only data of 40 non-ambulance users who did not visit a GP and 47 ambulance users were included

TABLE 2. Time interval comparison between ambulance users and non-ambulance users*

\begin{tabular}{|c|c|c|c|c|c|c|c|c|}
\hline \multirow[t]{2}{*}{ Phaset } & \multirow{2}{*}{$\begin{array}{l}\text { Ambulance users } \\
(n=48)\end{array}$} & \multicolumn{6}{|c|}{ Non-ambulance users $(n=54)$} & \multirow[t]{2}{*}{$P$ value } \\
\hline & & Visited GP (n=12) & $P$ value $\neq$ & $\begin{array}{c}\text { Did not visit GP } \\
(n=42)\end{array}$ & $P$ value & $P$ value§ & All & \\
\hline I & $77.5(21.25-278.75)$ & $1470(720-3165)$ & 0.001 & $440(75-3023)$ & 0.004 & 0.235 & $720(108.75-3023)$ & $<0.001$ \\
\hline II & $32(29-41.5)$ & $76(56.25-123)$ & $<0.001$ & $31.5(19.5-52.5)$ & 0.743 & $<0.001$ & $44.5(23.25-66.25)$ & $<0.001$ \\
\hline III & $8(2.25-12.5)$ & $24(15.75-39.25)$ & $<0.001$ & $11.5(7.75-25.5)$ & 0.006 & 0.014 & $15(8.75-27.75)$ & $<0.001$ \\
\hline$I+I I+I I I$ & $120(75.25-304.5)$ & $1849.5(1200-4286.25)$ & $<0.001$ & $480.5(160-3081.25)$ & $<0.001$ & 0.074 & $1182(180.75-3224.5)$ & $<0.001$ \\
\hline \multicolumn{9}{|c|}{$\begin{array}{l}\text { Abbreviation: GP = general practitioner } \\
* \text { Data are presented as median (interquartile range) time }(\mathrm{min}) \\
\dagger \text { Phase I denotes time interval from onset to seek help; phase II from seeking help to arrival at emergency department; and phase III from arrival at } \\
\text { emergency department to medical consultation } \\
\text { † Comparison with ambulance users (Mann-Whitney } U \text { test) } \\
\S \text { Comparison between non-ambulance users who visited or did not visit GP (Mann-Whitney } U \text { test) }\end{array}$} \\
\hline
\end{tabular}

users was 15 minutes $(\mathrm{P}<0.001)$. The time from onset of stroke to medical consultation in the ED for ambulance users was 120 minutes, whereas that for non-ambulance users was 1182 minutes $(\mathrm{P}<0.001)$.

Of the 102 patients, 34 patients were treated with TPA. The reasons for not giving TPA were: uncertain onset time $(n=8)$, therapeutic window exceeded $(n=13)$, low National Institutes of Health Stroke Scale (NIHSS) score of $<5(n=52)$, high NIHSS score of $>25 \quad(n=16)$, intracerebral haemorrhage $(n=16)$, convulsions $(n=2)$, patient refused TPA $(n=2)$, and poor pre-morbidity $(n=6)$. There may be more than one reason per patient for not giving TPA. At 3 months after administration of TPA, five patients had excellent results (ie, reduction of $\geq 8$ points in NIHSS score), 11 had good results (ie, reduction of $\geq 4$ points in NIHSS score), 14 were static (ie, change of $<4$ points in NIHSS score), and four deteriorated (ie, increase of $\geq 4$ points in NIHSS score).

\section{Discussion}

In Hong Kong, calls to the emergency services are answered by the Police Force and the Fire Services Department, which provides ambulance and firefighting services. Our study found that overall time intervals were shorter in ambulance users than in non-ambulance users. Significantly more ambulance users had a medical consultation within the therapeutic window than did non-ambulance users. For phase I, ambulance users might have more awareness and called for help earlier than the nonambulance users. Compared with ambulance users, phase II was significantly longer for non-ambulance users who visited a GP, but not for patients who did not visit a GP. This might be because non-ambulance 
users who did not visit a GP went directly to the ED after calling for help. Ambulance users had a shorter phase III than did non-ambulance users. Nonambulance users who did not visit a GP had shorter phase II, phase III, and overall time from onset to medical consultation than did those who visited a GP.

A study in Australia showed that fewer than $50 \%$ of stroke patients who called for an ambulance could correctly identify stroke from the symptoms. ${ }^{6}$ A study in Germany on calling for emergency assistance showed similar findings. ${ }^{7}$ An important finding in these papers was the importance of advice and assistance immediately after stroke onset ${ }^{6,7}$; one third of these patients were unable to make decision themselves. ${ }^{6}$ How stroke patients interpreted their symptoms, developed coping mechanisms, and engaged others prior to an emergency call for help was unclear. ${ }^{6}$ The process of seeking "lay referral" to call for an ambulance was not studied. ${ }^{6}$

In North America, a study to compare hospital arrivals showed no major differences between the situation in 2002 and that in 2009. ${ }^{8}$ The Get With The Guidelines-Stroke Program included over 413147 ischaemic stroke patients from 287 hospitals; of these, $26.8 \%$ of patients arrived at the ED in $\leq 3.5$ hours. The percentage of stroke patients who arrived within the therapeutic window did not change during the studied period. The authors suggested that further effort would be necessary to increase the proportion of patients arriving within the therapeutic window. ${ }^{8}$

Our findings are important for clinical applications. In our literature search, we could not find study from Hong Kong on how to shorten the time prior to hospital arrival. We believe that appropriate education can change the mindset of the public. If patients can recognise the signs and symptoms of stroke, they are more likely to call an ambulance in a timely manner, and thus will have a higher chance of receiving TPA treatment within the therapeutic window.

There are several limitations to the present study. The study was conducted in a single centre within a 6 -month period. Although the sample size was limited by the study period, significant results were found. The study involved asking patients to recall the time of stroke onset, time of calling for help, and time of arrival at the ED. To mitigate any potential recall bias, the recalled information was cross-checked by relatives or a GP, and the time interval was short.

In recent years, the Hong Kong Stroke Fund has provided much public education, promoting recognition of acute stroke using the mnemonic “FAST" (談笑用兵). Here, “F” (face, 笑) refers to facial asymmetry, “A” (arms, 用) refers to weakness or numbness of the limbs, "S" (speech, 談) refers to slurring of speech, and " $\mathrm{T}$ " (time, 兵) refers to calling for immediate assistance. ${ }^{9}$

A study in Japan compared the effectiveness of different media on how to improve public knowledge of stroke. The authors found that television was more effective than printed newspapers. ${ }^{10}$ A combination of different media was found to be most effective. ${ }^{10}$ Structured community-based public education can improve public knowledge on stroke. ${ }^{10}$

Some patients voluntarily mentioned their reasons for not calling the emergency services for an ambulance. Some years ago, there was a publicity campaign to reduce ambulance misuse. ${ }^{11}$ Although the original message was not to misuse the ambulance service, the effect was long-lasting. Some patients still believe that there is always someone who is in greater need of an ambulance. Thus, these patients believe that they can travel to the ED themselves and are unaware of the urgency. Because these patients are unaware of the therapeutic window, they do not hurry to the ED. Public education, especially to encourage proper use of ambulance services is required. ${ }^{12}$ Public education on recognition of the symptoms and signs of stroke and on how to better utilise the emergency services is of the utmost importance.

\section{Conclusion}

The present study shows that the means of transport to the ED is an important aspect in effective stroke treatment. Stroke patients who call the emergency services are more likely to be treated effectively with TPA within the therapeutic window. Increasing public awareness of the signs and symptoms of acute stroke, and of the need to call the emergency services in case of stroke is critical.

\section{Acknowledgement}

Thanks to all patients and their relatives, without their support this study could not be completed.

\section{Author contributions}

All authors have made substantial contributions in designing the study, collecting data, analysis and interpretation of data, drafting, and critical revision of the article.

\section{Funding/support}

This research has received no specific grant from any funding agency in the public, commercial, or not-for-profit sectors.

\section{Declaration}

All authors have disclosed no conflict of interest. All authors had full access to the data, contributed to the study, approved the final version for publication, and take responsibility for its accuracy and integrity.

\section{Ethical approval}

This study was approved by the Ethics Committee, Kowloon 
West Cluster (REC no. KW/EX-16-183(105-10)). Written informed consent was provided by all patients.

\section{References}

1. National Institute of Neurological Disorders and Stroke rt-PA Stroke Study Group. Tissue plasminogen activator for acute ischemic stroke. N Engl J Med 1995;333:1581-7.

2. Hacke W, Donnan G, Fieschi C, et al. Association of outcome with early stroke treatment: pooled analysis of ATLANTIS, ECASS, and NINDS rt-PA stroke trials. Lancet 2004;363:768-74.

3. Strbian D, Ringleb P, Michel P, et al. Ultra-early intravenous stroke thrombolysis: do all patients benefit similarly? Stroke 2013;44:2913-6.

4. Lau KK, Yeung KM, Chiu LH, et al. Delays in the presentation of stroke patients to hospital and possible ways of improvement. Hong Kong J Emerg Med 2003;10:76-80.

5. Hachinski V, Donnan GA, Gorelick PB, et al. Stroke: working toward a prioritized world agenda. Cerebrovasc Dis 2010;30:127-47.

6. Mosley I, Nicol M, Donnan G, Patrick I, Dewey H. Stroke symptoms and the decision to call for an ambulance. Stroke
2007;38:361-6.

7. Handschu R, Poppe R, Rauss J, Neundörfer B, Erbguth F. Emergency calls in acute stroke. Stroke 2003;34:1005-9.

8. Tong D, Reeves MJ, Hernandez AF, et al. Times from symptom onset to hospital arrival in the Get With the Guidelines-Stroke Program 2002 to 2009: temporal trends and implications. Stroke 2012;43:1912-7.

9. Hong Kong Stroke Fund. Acute Stroke ManagementFAST. 2017. Available from: http://www.strokefund.org/ eng/prevention_part1.php. Accessed 22 Sep 2017.

10. Miyamatsu N, Okamura T, Nakayama $\mathrm{H}$, et al. Public awareness of early symptoms of stroke and information sources about stroke among the general Japanese population: the acquisition of stroke knowledge study. Cerebrovasc Dis 2013;35:241-9.

11. Hong Kong's Information Services Department. $「$ 切勿濫 用救護車」標語創作比賽. 2009. Available from: http:// www.info.gov.hk/gia/general/200906/16/P200906160205. htm. Accessed 22 Sep 2017.

12. Becker K, Fruin M, Gooding T, Tirschwell D, Love $\mathrm{P}$, Mankowski T. Community-based education improves stroke knowledge. Cerebrovasc Dis 2001;11:34-43. 